\title{
MODIFIKASI ALGORITMA VIGENÈRE CIPHER MENGGUNAKAN METODE CATALAN NUMBER DAN DOUBLE COLUMNAR TRANSPOSITION
}

\author{
Guruh Marindra Pratama, E.Nurmiyati Tamatjita \\ Program Studi Teknik Informatika \\ Sekolah Tinggi Teknologi Adisutjipto Yogyakarta \\ informatika@stta.ac.id
}

\begin{abstract}
Vigenère Cipher is one of the well-known ciphering algorithms of the past. Modifications to Vigenere Cipher algorithm is made to improve its security, making it more difficult to decipher by a cryptanalyst. Due to the nature of the algorithm, these measures have to be taken to maintain the confidentiality of ciphered data. This research modified the Vigenère Cipher using Catalan Numbers method and Double Columnar Transposition. Catalan Numbers method is a mathematical method used to randomize the initial key so as to generate a key which is longer and having stronger characteristics; a key which is harder to guess, either by cryptanalysts or by key-deciphering methods. In addition to the first method, Double Columnar Transposition is used to rearrange the position of data in the generated ciphertext in order to make it appear more random, hence slowing down the cryptanalysis process of the encrypted text. Double Columnar Transposition is done by applying columnar transposition twice to the ciphered text. The applied modifications to Vigenère Cipher are then tested using Kasiski Examination. Resulting ciphertexts are known to have randomised characteristics, which made it difficult to guess the ciphering method used to generate the ciphertexts. Tests done using Kasiski Examination $\{1,2,4\}$ proven that the ciphertexts passed the test, hence putting down the possibility of easy deciphering, and the modifications successfully provided a better and stronger encryption to the Vigenère Cipher.
\end{abstract}

Keywords : Vigenère Cipher, Catalan Number, Double Columnar Transposition

\section{Pendahuluan}

Perkembangan teknologi komputer dan jaringan komputer yang semakin pesat, tidak hanya memberikan dampak positif seperti kemudahan dan kepraktisan dalam mengolah informasi dan data, namun juga dapat memberikan dampak negatif seperti penyalahgunaan informasi dan data, hal ini dikarenakan manusia yang selalu bereksperimen dalam mengembangkan teknologi komputer dan juga mencari celah atau kelemahan pada sistem komputer. Data dan informasi tidak cukup pengembangannya hanya difokuskan pada kemudahan dan kepraktisan saja dalam mengolah dan mengaksesnya, namun dibutuhkan juga sistem pengamanan yang memadai dan terjamin, salah satu cara yang paling baik digunakan untuk mengamankan data menggunakan metode kriptografi.

Kekuatan metode kriptografi bukan terletak pada hasil enkripsi atau ciphertext, namun terletak pada kunci yang digunakan. Kunci pada kriptografi dapat dikatakan sebagai jantung pertahanan pengamanan data, karena kunci merupakan alat yang digunakan untuk menjembatani proses enkripsideskripsi atau deskripsi-enkripsi (Mollin, 2007). Algoritma kunci pada kriptografi dibedakan menjadi dua bagian, yaitu algortima kunci simetri dan algortima kunci asimetri. Algoritma kunci simetri seperti Vigenère Cipher (Kurniawan, 2004).

Pada penelitian tugas akhir ini, penulis memilih algoritma Vigenère Cipher untuk mengamankan dokumen. Vigenère Cipher merupakan algoritma kunci simetri yang menggunakan substitusi plialfabetic dengan melakukan subsitusi antara huruf plaintext dan huruf kunci yang berpadanan letaknya. Kelemahan pada Vigenère Cipher adalah kunci berulang, jika kriptanalis dapat menebak 
dengan tepat panjang kunci, maka ciphertext dengan mudah dipecahkan menggunakan Metode Kasiski (Munir, 2004). Metode Kasiski dapat diartikan sebagai penebakan panjang kunci melalui serangkaian perhitungan pola huruf $n$-graf, jika Dari permasalahan ini, maka penulis ingin memperbaiki celah keamanan pada kekuatan kunci Vigenère Cipher, dengan mengubah kunci menjadi lebih panjang dan acak menggunakan metode perhitungan Catalan Number.

\section{Metodologi Penelitian}

\subsection{Algoritma Kriptografi Klasik}

Sebelum komputer ada, kriptografi dilakukan dengan menggunakan pensil dan kertas. Algoritma kriptografi (cipher) yang digunakan saat itu, dinamakan juga algoritma klasik, adalah berbasis karakter, yaitu enkripsi dan deskripsi dilakukan pada setiap karakter pesan. Semua algoritma klasik termasuk ke dalam sistem kriptografi simetris dan digunakan jauh sebelum kriptografi kunci publik ditemukan. Kriptografi klasik memiliki beberapa ciri yaitu berbasis karakter dimana karakter tersebut disubstitusikan dan dipermutasikan (Wadhwa, Hussain, 2010) menggunakan pena dan kertas saja sebelum ada komputer dan kriptografi klasik termasuk ke dalam kriptografi kunci simetris.

\subsection{Vigenère Cipher}

Vigenère Cipher mungkin adalah contoh terbaik dari cipher alphabet-majemuk 'manual'. Algoritma ini dipublikasikan oleh diplomat perancis, Blaise de Vigènere pada abad 16. Vigènere Cipher dipublikasikan pada tahun 1586. Vigènere Cipher menggunakan bujursangakar Vigènere untuk melakukan enkripsi. Kolom paling kiri dari bujursangkar menyatakan huruf-hurf kunci, sedangkan baris paling atas menyatakan huruf-huruf plainteks. Jumlah pergesaran huruf plainteks ditentukan nilai numerik huruf kunci tersebut ( yaitu, $\mathrm{A}=0, \mathrm{~B}=1, \mathrm{C}=2, \ldots, \mathrm{Z}=25$ ).

Tabel 1 Bujursangkar vigènere

\begin{tabular}{|c|c|c|c|c|c|c|c|c|c|c|c|c|c|c|c|c|c|c|c|c|c|c|c|c|c|c|}
\hline & $A$ & B & C & $\mathrm{D}$ & $E$ & $\mathrm{~F}$ & $\mathrm{G}$ & $\mathrm{H}$ & I & $\mathrm{J}$ & $\mathrm{K}$ & $\mathrm{L}$ & $\mathrm{M}$ & $\mathrm{N}$ & $\mathrm{O}$ & $P$ & $Q$ & $\mathrm{R}$ & $S$ & $\mathrm{~T}$ & $\mathrm{U}$ & V| & W & X & $Y$ & $\angle$ \\
\hline A & $\mathrm{A}$ & B & $\mathrm{C}$ & $\mathrm{D}$ & $\mathrm{E}$ & $\mathbf{F}$ & G & $\mathrm{H}$ & I & $\mathbf{J}$ & $\mathrm{K}$ & $\mathrm{L}$ & $\mathrm{M}$ & $\mathrm{N}$ & $\mathrm{O}$ & $\mathrm{P}$ & $Q$ & $\mathrm{R}$ & $\mathrm{S}$ & $\mathrm{T}$ & $\mathrm{U}$ & $\mathrm{V}$ & $\mathrm{W}$ & $\mathrm{X}$ & $Y$ & Z \\
\hline $\mathrm{B}$ & $\mathrm{B}$ & $\mathrm{C}$ & $\mathrm{D}$ & $\mathrm{E}$ & & $\vec{J}$ & $\mathrm{H}$ & 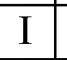 & $\mathrm{J}$ & $\mathrm{K}$ & $\mathrm{L}$ & $M$ & $\mathrm{~N}$ & $\mathrm{O}$ & $\mathrm{P}$ & $\mathrm{Q}$ & $\mathrm{R}$ & $\mathrm{S}$ & $\mathrm{T}$ & $\mathrm{U}$ & $\mathrm{V}$ & $\mathrm{W}$ & $\mathrm{X}$ & $Y$ & 7 & $\mathrm{~A}$ \\
\hline C & $\mathrm{C}$ & $\mathrm{D}$ & $E$ & $\mathrm{~F}$ & $G$ & $\mathrm{H}$ & I & $\mathrm{J}$ & $\mathrm{K}$ & $\mathrm{L}$ & $\mathrm{M}$ & $\mathrm{N}$ & $\mathrm{O}$ & $\mathrm{P}$ & $\mathrm{Q}$ & $\mathrm{R}$ & $\mathrm{S}$ & $\mathrm{T}$ & $\bar{U}$ & $\mathrm{~V}$ & $\mathrm{~W}$ & $\mathrm{X}$ & $Y$ & $Z$ & $\mathrm{~A}$ & $\bar{B}$ \\
\hline D & $\mathrm{D}$ & $\mathrm{E}$ & $\bar{F}$ & $\mathrm{G}$ & $\mathrm{H}$ & I & $\mathbf{J}$ & $\mathrm{K}$ & $\mathrm{L}$ & $\mathrm{M}$ & $\mathrm{N}$ & $\mathrm{O}$ & $P$ & $\bar{Q}$ & $\mathrm{R}$ & $\bar{S}$ & $\mathrm{~T}$ & $\overline{\mathrm{U}}$ & $\mathrm{V}$ & $\mathrm{W}$ & $\mathrm{X}$ & $\mathrm{Y}$ & $\bar{Z}$ & $\mathrm{~A}$ & $\bar{B}$ & $\bar{C}$ \\
\hline$E$ & $E$ & $\bar{F}$ & $\mathrm{G}$ & $\mathrm{H}$ & I & $\mathbf{J}$ & K & $\mathrm{L}$ & $\mathrm{M}$ & $\mathrm{N}$ & $\mathrm{O}$ & $P$ & Q & $\mathrm{R}$ & $S$ & $\mathrm{~T}$ & $\mathrm{U}$ & $\bar{V}$ & $\mathrm{~W}$ & $\mathrm{X}$ & $\mathrm{Y}$ & $Z$ & $\bar{A}$ & B & $\mathrm{C}$ & $\mathrm{D}$ \\
\hline $\mathrm{F}$ & $\mathrm{F}$ & $\mathrm{G}$ & $\mathrm{H}$ & I & $\mathbf{J}$ & K & $\mathrm{L}$ & $\mathrm{M}$ & $\mathrm{N}$ & $\mathrm{O}$ & $\mathrm{P}$ & $Q$ & $\mathrm{R}$ & $\mathrm{S}$ & $\mathrm{T}$ & $\mathrm{U}$ & $\mathrm{V}$ & $\mathrm{W}$ & $\mathrm{X}$ & $\mathrm{Y}$ & $\mathrm{Z}$ & $\mathrm{A}$ & B & $\mathrm{C}$ & D & $\bar{E}$ \\
\hline $\mathrm{G}$ & $\mathrm{G}$ & $\mathrm{H}$ & I & $\mathbf{J}$ & $\overline{\mathrm{K}}$ & $\mathrm{L}$ & $\mathrm{M}$ & $\mathrm{N}$ & $\mathrm{O}$ & I & $\mathrm{Q}$ & $\mathrm{R}$ & S & $\mathrm{T}$ & $\mathrm{U}$ & $\mathrm{V}$ & $\mathrm{W}$ & $\mathrm{X}$ & $\bar{Y}$ & $\mathrm{Z}$ & $\mathrm{A}$ & $\mathrm{B}$ & $\mathrm{C}$ & $\bar{D}$ & $\bar{E}$ & $\bar{F}$ \\
\hline $\mathrm{H}$ & $\mathrm{H}$ & $\mathrm{I}$ & $\bar{J}$ & K & $\mathrm{L}$ & $\mathrm{M}$ & $\mathrm{N}$ & $\mathrm{O}$ & $\mathrm{P}$ & Q & $\mathrm{R}$ & $\overline{\mathrm{S}}$ & $\mathrm{T}$ & $\mathrm{U}$ & $\mathrm{V}$ & $\mathrm{W}$ & $\mathrm{X}$ & $\mathrm{Y}$ & Z & $\mathrm{A}$ & B & $\mathrm{C}$ & $\bar{D}$ & $\mathrm{E}$ & $\bar{F}$ & $\mathrm{G}$ \\
\hline I & I & $\mathrm{J}$ & $\mathrm{K}$ & $\mathrm{L}$ & $\mathrm{M}$ & $\mathrm{N}$ & $\mathrm{O}$ & $\mathrm{P}$ & $\mathrm{Q}$ & $\mathrm{R}$ & $\mathrm{S}$ & $\mathrm{T}$ & $\mathrm{U}$ & $\mathrm{V}$ & $\mathrm{W}$ & $\mathrm{X}$ & $\mathrm{Y}$ & $Z$ & $\mathrm{~A}$ & B & $\mathrm{C}$ & $\mathrm{D}$ & $E$ & $\mathrm{~F}$ & $\mathrm{G}$ & $\mathrm{H}$ \\
\hline $\mathrm{J}$ & $\mathrm{J}$ & $\mathrm{K}$ & $\mathrm{L}$ & $\mathrm{M}$ & $\mathrm{N}$ & $\mathrm{O}$ & $\mathrm{P}$ & $\mathrm{Q}$ & $\mathrm{R}$ & $\mathrm{S}$ & $\mathrm{T}$ & $\mathrm{U}$ & $\mathrm{V}$ & $\mathrm{W}$ & $\mathrm{X}$ & $\mathrm{Y}$ & $Z$ & $\mathrm{~A}$ & B & $\mathrm{C}$ & $\mathrm{D}$ & $\mathrm{E}$ & $\mathrm{F}$ & $G$ & $\mathrm{H}$ & I \\
\hline $\mathrm{K}$ & $\mathrm{K}$ & $\mathrm{L}$ & $\mathrm{M}$ & $\mathrm{N}$ & $\mathrm{O}$ & $\mathrm{P}$ & $\mathrm{Q}$ & $\mathrm{R}$ & $\mathrm{S}$ & $\mathrm{T}$ & $\mathrm{U}$ & $\mathrm{V}$ & $\mathrm{W}$ & $\mathrm{X}$ & $\mathrm{Y}$ & $Z$ & $\mathrm{~A}$ & B & $\mathrm{C}$ & $\mathrm{D}$ & $\mathrm{E}$ & $\mathrm{F}$ & $G$ & $\mathrm{H}$ & 1 & $\mathrm{~J}$ \\
\hline $\mathbf{L}$ & $\mathrm{L}$ & $\mathrm{M}$ & $\mathrm{N}$ & $\mathrm{O}$ & $\mathrm{P}$ & $\bar{Q}$ & $\mathrm{R}$ & $\mathrm{S}$ & $\mathrm{T}$ & $\mathrm{U}$ & $\mathrm{V}$ & $\mathrm{W}$ & $\mathrm{X}$ & $\mathrm{Y}$ & $Z$ & $\mathrm{~A}$ & B & $\mathrm{C}$ & $\mathrm{D}$ & $E$ & $\mathrm{~F}$ & $\mathrm{G}$ & $\mathrm{H}$ & I & & $\mathrm{K}$ \\
\hline $\mathrm{M}$ & $\mathrm{M}$ & $\mathrm{N}$ & $\mathrm{O}$ & $\mathrm{P}$ & $\mathrm{O}$ & $\mathrm{R}$ & $\mathrm{S}$ & $\mathrm{T}$ & $\mathrm{U}$ & $\mathrm{V}$ & $\mathrm{W}$ & $X$ & $Y$ & $\mathrm{Z}$ & $\mathrm{A}$ & $\mathrm{B}$ & $\mathrm{C}$ & $\mathrm{D}$ & $E$ & $\mathrm{~F}$ & $\mathrm{G}$ & $\mathrm{H}$ & $\mathrm{I}$ & $\mathrm{J}$ & $\mathrm{K}$ & $\mathrm{L}$ \\
\hline $\mathrm{N}$ & \begin{tabular}{|l|}
$\mathrm{N}$ \\
\end{tabular} & $\mathrm{O}$ & $\bar{P}$ & $\mathrm{Q}$ & $\mathrm{R}$ & $\mathrm{S}$ & $\mathrm{T}$ & $\overline{\mathrm{U}}$ & $\overline{\mathrm{V}}$ & $\mathrm{W}$ & $\mathrm{X}$ & $\mathrm{Y}$ & $\mathrm{Z}$ & $\mathrm{A}$ & $\mathrm{B}$ & $\mathrm{C}$ & $\mathrm{D}$ & $\mathrm{E}$ & $\bar{F}$ & $\mathrm{G}$ & $\overrightarrow{\mathrm{H}}$ & $\mathrm{I}$ & $\mathrm{J}$ & $\mathrm{K}$ & $\mathrm{L}$ & $\mathrm{M}$ \\
\hline $\mathrm{O}$ & 0 & $\mathrm{P}$ & $\mathrm{Q}$ & $\mathrm{R}$ & $S$ & $\mathrm{~T}$ & $\mathrm{U}$ & $\mathrm{V}$ & $\mathrm{W}$ & $\mathrm{X}$ & $\mathrm{Y}$ & $\mathrm{Z}$ & A & B & $\mathrm{C}$ & $\mathrm{D}$ & $E$ & $\mathrm{~F}$ & $\mathrm{G}$ & $\mathrm{H}$ & I & $\mathbf{J}$ & $\mathrm{K}$ & $\mathrm{L}$ & $\mathrm{M}$ & $\mathrm{N}$ \\
\hline $\mathrm{P}$ & $\mathrm{P}$ & $Q$ & $\mathrm{R}$ & $\mathrm{S}$ & $\mathrm{T}$ & $\mathrm{U}$ & $\mathrm{V}$ & $\mathrm{W}$ & $X$ & $Y$ & $Z$ & $\mathrm{~A}$ & B & $\mathrm{C}$ & $\mathrm{D}$ & $\mathrm{E}$ & $\mathrm{F}$ & $\mathrm{G}$ & $\mathrm{H}$ & 1 & $\mathbf{J}$ & $\mathrm{K}$ & $\mathrm{L}$ & $\mathrm{M}$ & $\mathrm{N}$ & $\mathrm{O}$ \\
\hline 0 & Q & $\mathrm{R}$ & $\mathrm{S}$ & $\mathrm{T}$ & $\mathrm{U}$ & $\mathrm{V}$ & $\mathrm{W}$ & $X$ & $\mathrm{Y}$ & $Z$ & $\mathrm{~A}$ & B & $\mathrm{C}$ & $\mathrm{D}$ & $\mathrm{E}$ & $\mathrm{F}$ & $G$ & $\mathrm{H}$ & $\mathrm{I}$ & $\mathrm{J}$ & $\mathrm{K}$ & $\mathrm{L}$ & $\mathrm{M}$ & $\mathrm{N}$ & $\mathrm{O}$ & $\mathrm{P}$ \\
\hline $\mathrm{R}$ & $\mathrm{R}$ & $\mathrm{S}$ & $\mathrm{T}$ & $\mathrm{U}$ & $\mathrm{V}$ & $\mathrm{W}$ & $\mathrm{X}$ & $\mathrm{Y}$ & $Z$ & $\mathrm{~A}$ & B & $\mathrm{C}$ & $\mathrm{D}$ & $\mathrm{E}$ & $\mathrm{F}$ & $\mathrm{G}$ & $\mathrm{H}$ & I & $\mathrm{J}$ & $\mathrm{K}$ & $\mathrm{L}$ & $\mathrm{M}$ & $\mathrm{N}$ & $\mathrm{O}$ & $\mathrm{P}$ & $\mathrm{Q}$ \\
\hline $\mathrm{S}$ & $\mathrm{S}$ & $\mathrm{T}$ & $\mathrm{U}$ & $\mathrm{V}$ & $\mathrm{W}$ & $\mathrm{X}$ & $\mathrm{Y}$ & $Z$ & $\mathrm{~A}$ & B & $\mathrm{C}$ & $\mathrm{D}$ & $E$ & $\mathrm{~F}$ & $\mathrm{G}$ & $\mathrm{H}$ & I & $\mathrm{J}$ & $\mathrm{K}$ & $\mathrm{L}$ & $\mathrm{M}$ & $\mathrm{N}$ & $\mathrm{O}$ & $P$ & $\mathrm{Q}$ & $\mathrm{R}$ \\
\hline $\mathrm{T}$ & $\mathrm{T}$ & $\mathrm{U}$ & $\mathrm{V}$ & $W$ & $X$ & $\mathrm{Y}$ & $Z$ & $\mathrm{~A}$ & $\mathrm{~B}$ & $\mathrm{C}$ & $\mathrm{D}$ & $\mathrm{E}$ & $\mathrm{F}$ & $\mathrm{G}$ & $\mathrm{H}$ & $\mathrm{I}$ & $\mathrm{J}$ & $\mathrm{K}$ & $\mathrm{L}$ & $\mathrm{M}$ & $\mathrm{N}$ & $\mathrm{O}$ & $\mathrm{P}$ & $Q$ & $\mathrm{R}$ & $\mathrm{S}$ \\
\hline $\mathrm{U}$ & \begin{tabular}{|l|}
$\mathrm{U}$ \\
\end{tabular} & $\mathrm{V}$ & $\mathrm{W}$ & $\mathrm{X}$ & $\mathrm{Y}$ & $Z$ & $\mathrm{~A}$ & B & $\mathrm{C}$ & $\mathrm{D}$ & $\mathrm{E}$ & $\mathrm{F}$ & $\mathrm{G}$ & $\mathrm{H}$ & I & $J$ & $\mathrm{~K}$ & $\mathrm{~L}$ & $\mathrm{M}$ & $\mathrm{N}$ & $\mathrm{O}$ & $\mathrm{P}$ & $Q$ & $\mathrm{R}$ & $\mathrm{S}$ & $\mathrm{T}$ \\
\hline
\end{tabular}




\begin{tabular}{|c|c|c|c|c|c|c|c|c|c|c|c|c|c|c|c|c|c|c|c|c|c|c|c|c|c|c|}
\hline V & V & W & X & Y & Z & A & B & C & D & E & F & G & H & I & J & K & L & M & N & O & P & Q & R & S & T & U \\
\hline W & W & X & Y & Z & A & B & C & D & E & F & G & H & I & J & K & L & M & N & O & P & Q & R & S & T & U & V \\
X & X & Y & Z & A & B & C & D & E & F & G & H & I & J & K & L & M & N & O & P & Q & R & S & T & U & V & W \\
Y & Y & Z & A & B & C & D & E & F & G & H & I & J & K & L & M & N & O & P & Q & R & S & T & U & V & W & X \\
\hline Z & Z & A & B & C & D & E & F & G & H & I & J & K & L & M & N & O & P & Q & R & S & T & U & V & W & X & Y \\
\hline
\end{tabular}

\subsection{Metode Kasiski}

Metode Pengujian Kasiski adalah metode pengujian algoritma Vigenère Cipher dimana fungsi dari metode ini adalah untuk menganalisa panjang kunci yang digunakan oleh seorang kriptanalis dalam mengenkripsi suatu plaintext menjadi ciphertext. Aturan Metode Kasiski ini ialah dengan menganalisa himpunan deret huruf yang memiliki index kemunculan paling sering dalam ciphertext. Kemudian himpunan tersebut dieliminasi sehingga mendapatkan panjang kunci yang kemungkinan digunakan dalam proses enkripsi algoritma Vigenère Cipher tersebut.

\subsection{Perancangan Perangkat Lunak}

\subsubsection{Data Flow Diagram Context}

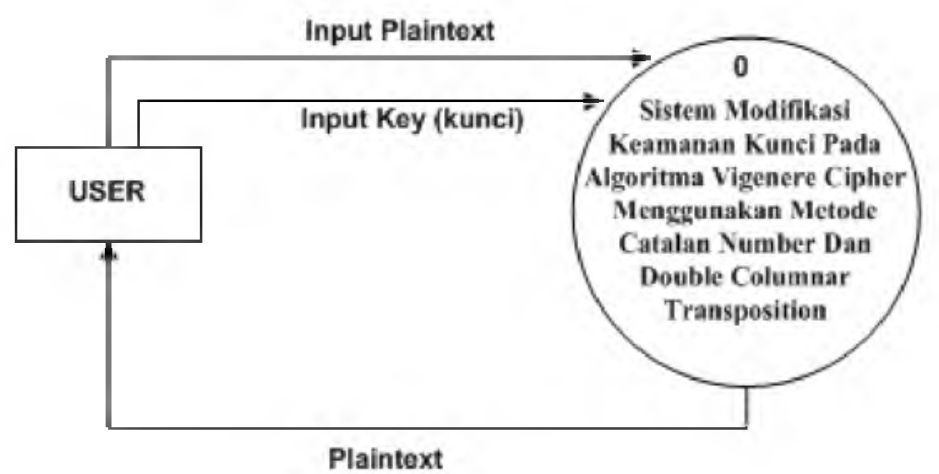

Gambar 1 Data Flow Diagram Context Modifikasi Algoritma Vigenère Cipher

Input data berupa plaintext dan juga kunci yang kemudian digunakan untuk proses enkripsi dan deskripsi data. Hasil dari proses sistem diatas merupakan plaintext yang akan diterima oleh user setelah data sebelumnya dienkripsi kemudian dideskripsi kembali menggunakan kunci yang sama. 


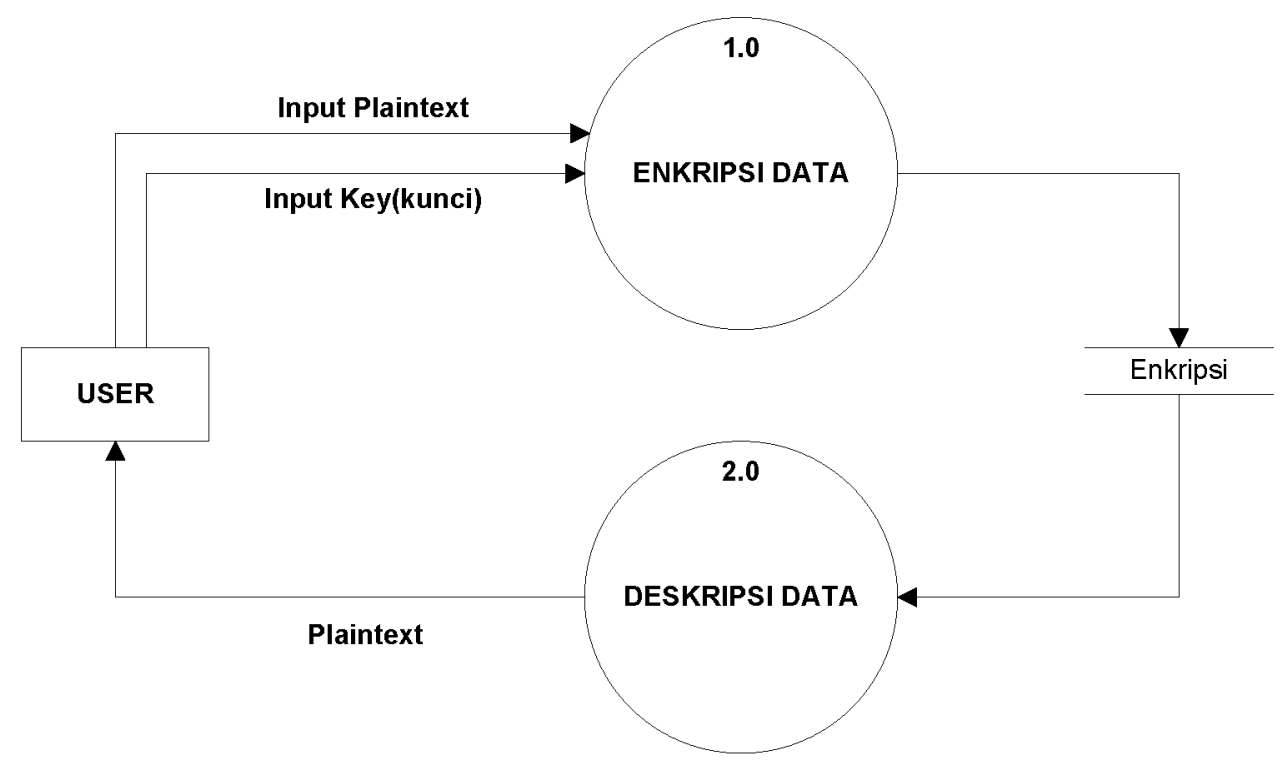

Gambar 2 Data Flow Diagram Level 0 Modifikasi Algoritma Vigenère Cipher

Pada DFD level 0, input data berupa plaintext dan juga kunci yang digunakan untuk melakukan proses enkripsi data, kemudian data storage berupa kunci dan ciphertext yang telah dimasukan terlebih dahulu. Setelah itu data storage ciphertext dan kunci digunakan pada proses deskripsi data yang menghasilkan output berupa plaintext sebagai hasil untuk user yang melakukan proses deskripsi.

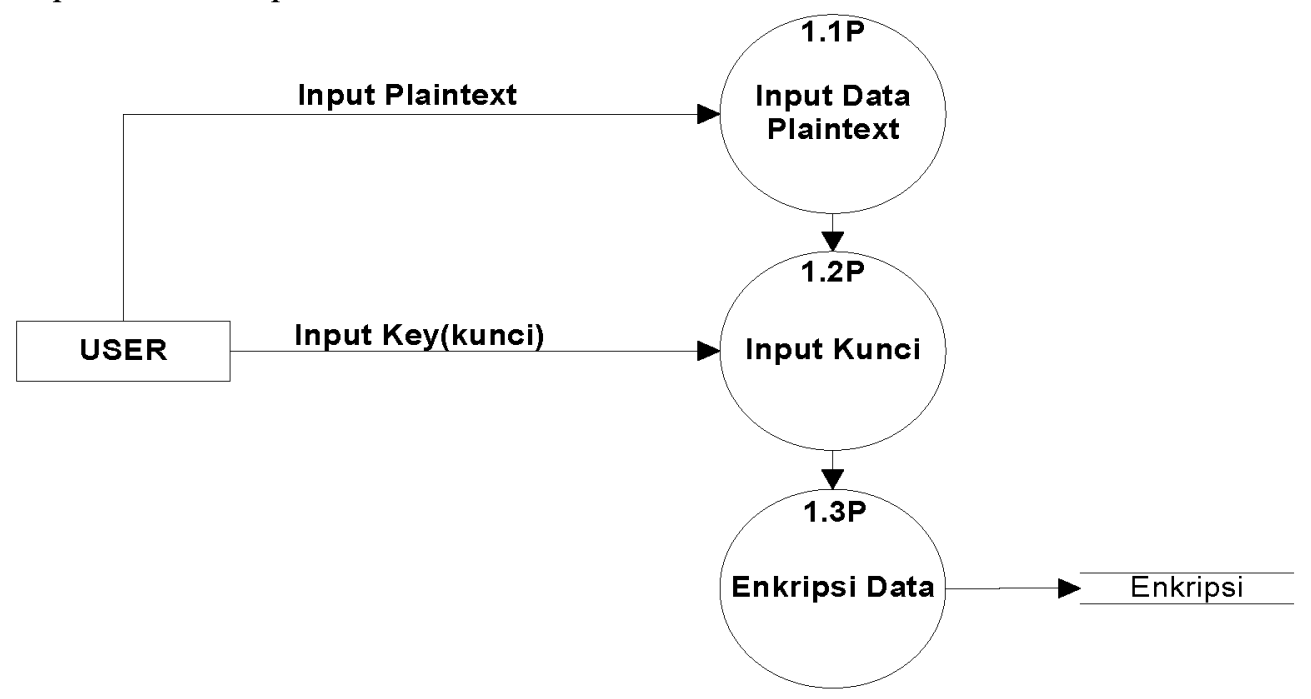

Gambar 3 Diagram Primitif - Data Flow Diagram Level l Enkripsi Modifikasi Vigenère Cipher

Gambar 3 menggambarkan diagram primitif - Data Flow Diagram Level 1 enkripsi modifikasi Vigenère Cipher. Input data berupa plaintext dan juga kunci yang digunakan untuk melakukan proses enkripsi data, kemudian data storage berupa kunci yang telah dimasukan terlebih dahulu. Hasil dari proses enkripsi berupa ciphertext yang diberikan kepada user dan juga kemudian ciphertext disimpan pada data storage ciphertext. 


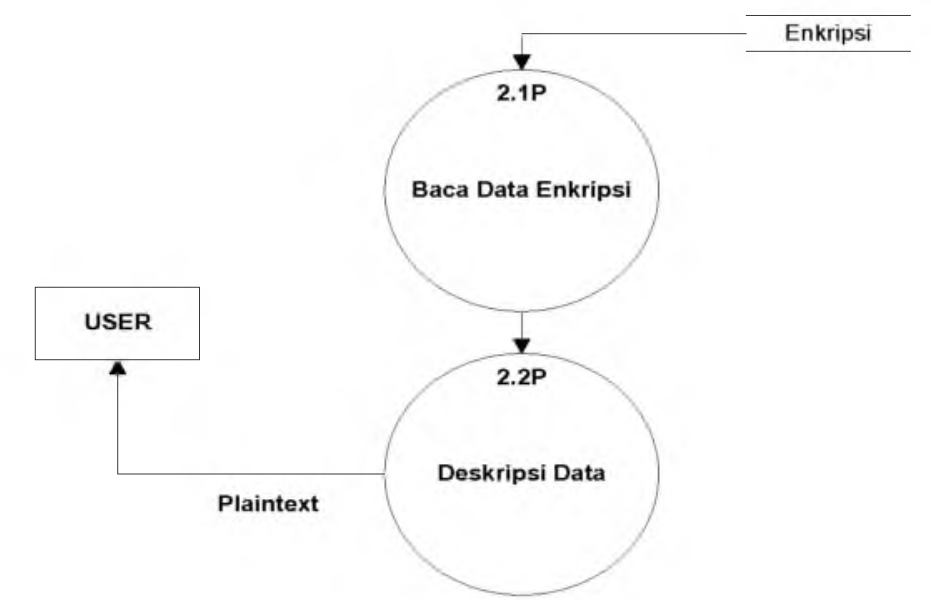

Gambar 4 Diagram Primitif - Data Flow Diagram Level 1 Deskripsi Modifikasi Vigenère Cipher

Gambar 4 menggambarkan diagram primitif - Data Flow Diagram Level 1 deskripsi modifikasi Vigenère Cipher. Input data berupa ciphertext dan juga kunci yang digunakan untuk melakukan proses deskripsi data yang diperoleh dari data storage. Kemudian data storage berupa kunci yang telah dimasukan terlebih dahulu. Data storage selanjutnya ialah merupakan ciphertext hasil enkripsi sebelumnya dan output berupa plaintext yang diberikan kepada user.

\subsubsection{Perancangan Modifikasi Algoritma}

Pada proses enkripsi menggunakan metode Catalan Number yang dilakukan adalah proses penerapan metode Catalan Number pada modifikasi kunci yang digunakan. Kunci tersebut akan diberikan rumus Catalan Number. Dari beberapa proses pembangkitan rumus Catalan Number atau yang disimbolkan dengan $C n$, memiliki bentuk persamaan umum yaitu:

$$
\boldsymbol{C n}=\frac{1}{n+1}\left(\begin{array}{c}
2 n \\
n
\end{array}\right)=\frac{(2 n) !}{(n+1) ! n !}, n>0 \quad \ldots .
$$

(sumber : http://mathworld.wolfram.com/CatalanNumber.html)

Kemudian proses pembentukan ciphertext diacak menggunakan metode Double Columnar Transposition sehingga hasil ciphertext lebih acak dan lebih sulit untuk dipecahkan oleh kriptanalis menggunakan metode Pengujian Kasiski.

\subsubsection{Perancangan Pengujian Aplikasi}

Metode yang digunakan untuk pengujian aplikasi kunci keamanan ini adalah dengan menggunakan Metode Kasiski dan analisa frekuensi. Selain itu juga digunakan aplikasi yang telah tersedia dari referensi internet yaitu aplikasi cryptohelper sebagai aplikasi untuk menguji program modifikasi algoritma Vigenère Cipher.

Metode Kasiski juga menggunakan analisis frekuensi di dalam salah satu langkahnya. Metode Kasiski ini akan bekerja lebih baik pada plaintext yang berasal dari bahasa Inggris, karena Metode Kasiski banyak menggunakan analisis frekuensi untuk bigram dan trigram. Langkah-langkah dalam menerapkan Metode Kasiski adalah:

1) Temukan kriptogram yang berulang. Bisa ditemui pada pesan-pesan yang cukup panjang

2) Hitung jarak antara kriptogram yang berulang

3) Hitung faktor pembagi dari jarak tersebut. Digunakan untuk memperkirakan panjang kunci

4) Tentukan irisan dari himpunan faktor pembagi tersebut. 
Metode Kasiski ini akan digunakan kemudian ketika kita akan menguji algoritma baru yang telah disusun (perbaikan Vigenère Cipher), yakni mencoba untuk mendeskripsi suatu pesan yang sudah ada. Gambar 3.2 adalah skema pengujian yang digunakan dalam perangkat lunak

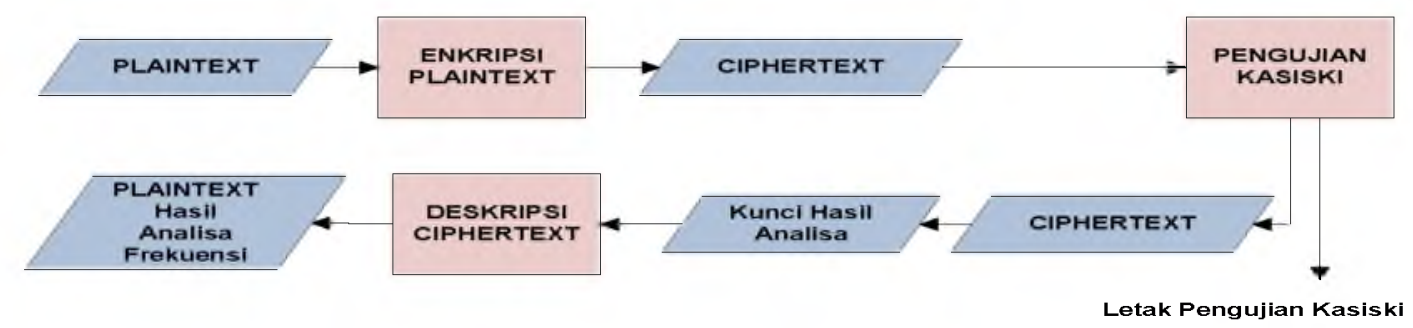

Gambar 5 Skema Letak Pengujian Aplikasi

\section{Hasil Dan Pembahasan}

\subsection{Hasil Rancangan}

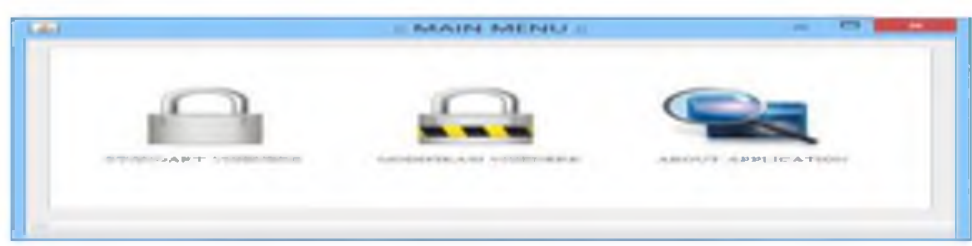

Gambar 6 Tampilan Menu Utama

Selanjutnya setalah memilih menu enkripsi/deskripsi menggunakan algoritma modifikasi pada aplikasi enkripsi ini proses yang terjadi adalah dengan memasukan plaintext berupa data teks yang akan dienkripsi pada field plaintext dan memasukan kunci pada field security key seperti gambar berikut:

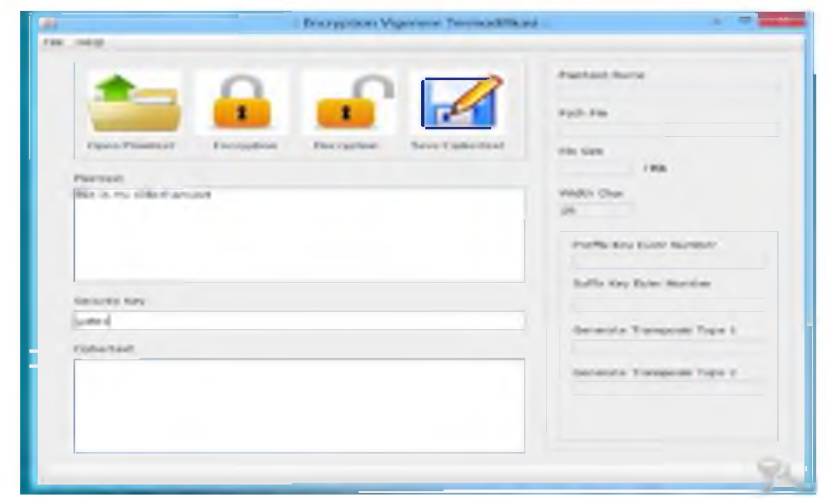

Gambar 7 Proses Input Plaintext dan Kunci

Setelah plaintext dan kunci dimasukan pada field masing-masing, klik tombol encryption sehingga plaintext tersebut akan diproses menggunakan metode modifikasi yang digunakan sehingga hasil ciphertext akan dicetak pada field ciphertext yang terdapat pada bagian bawah aplikasi seperti Gambar 8. 


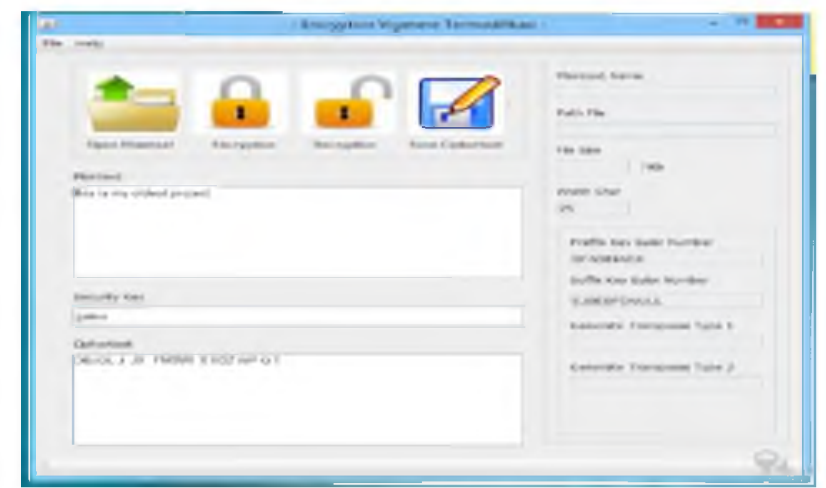

Gambar 8 Hasil Enkripsi Aplikasi

Setelah ciphertext dihasilkan dapat dilanjutkan pada proses penyimpanan. Proses penyimpanan aplikasi dilakukan dengan menekan tombol save sehingga ciphertext dan kunci disimpan pada file .txt yang nantinya dapat dibuka untuk proses deskripsi aplikasi. Berikut adalah tampilan hasil proses penyimpanan ciphertext dan kunci pada aplikasi. Hasil enkripsi disimpan pada file dengan format txt. Gambar 10 berikut adalah tampilan file enkrispi data diatas.

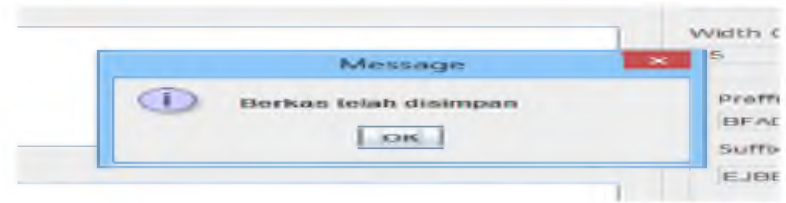

Gambar 9 Tampilan Hasil Proses Penyimpanan Ciphertext

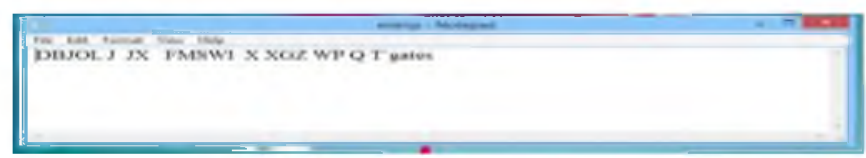

Gambar 10 File ciphertext yang tersimpan pada file txt

\subsection{Pembahasan}

Berikut merupakan uji hasil enkripsi aplikasi algoritma Vigenère Cipher yang telah dimodifikasi dan dibandingkan dengan algoritma Vigenère Cipher standar. Uji hasil tersebut dilakukan dengan menggunakan tools Pengujian Kasiski pada Tabel 2.

Tabel 2 Uji Fungsi Enkripsi Algoritma Modifikasi

\begin{tabular}{|c|c|c|}
\hline $\begin{array}{c}\text { Ciphertext Hasil Enkripsi } \\
\text { Modifikasi Algoritma Vigenère } \\
\text { Cipher }\end{array}$ & Kunci & $\begin{array}{l}\text { Ciphertext Hasil Enkripsi } \\
\text { Algoritma Vigenère Cipher }\end{array}$ \\
\hline $\begin{array}{l}\text { VRH HNKDCWKHKQ KCJOD } \\
\text { URU.UQEPRJKSHVHGTYV } \\
\text { TRUPL MXM LA WRBTICERQ } \\
\text { R LIUP MAZJ ZMGRAN HJU } \\
\text { JTXSHO } \\
\text { ITGSZPWWLFRUOFMWHRH } \\
\text { UYBRU S } \\
\text { UYCHUUTBRSBYXVVHURRL }\end{array}$ & $\mathrm{r}$ & $\begin{array}{l}\text { khx ead oy xzzs ivgaevx aj th ggde } \\
\text { nt ozta e kzmipw zmipwdegxskihr } \\
\text { xfr vsegumij rumlwetbgskihr if } \\
\text { rxtdrcx xzv phtmcak tsjs iljrsx } \\
\text { fsjew emkhxrlzctxafn hr hvrlsfrl } \\
\text { vsegumijj. tai hfpnpsiimc gw hbkz } \\
\text { ielsdltbsf tafijrs hr errdil dawi lye } \\
\text { iskjiumdztr sx wavi jvchkfztbsf }\end{array}$ \\
\hline
\end{tabular}




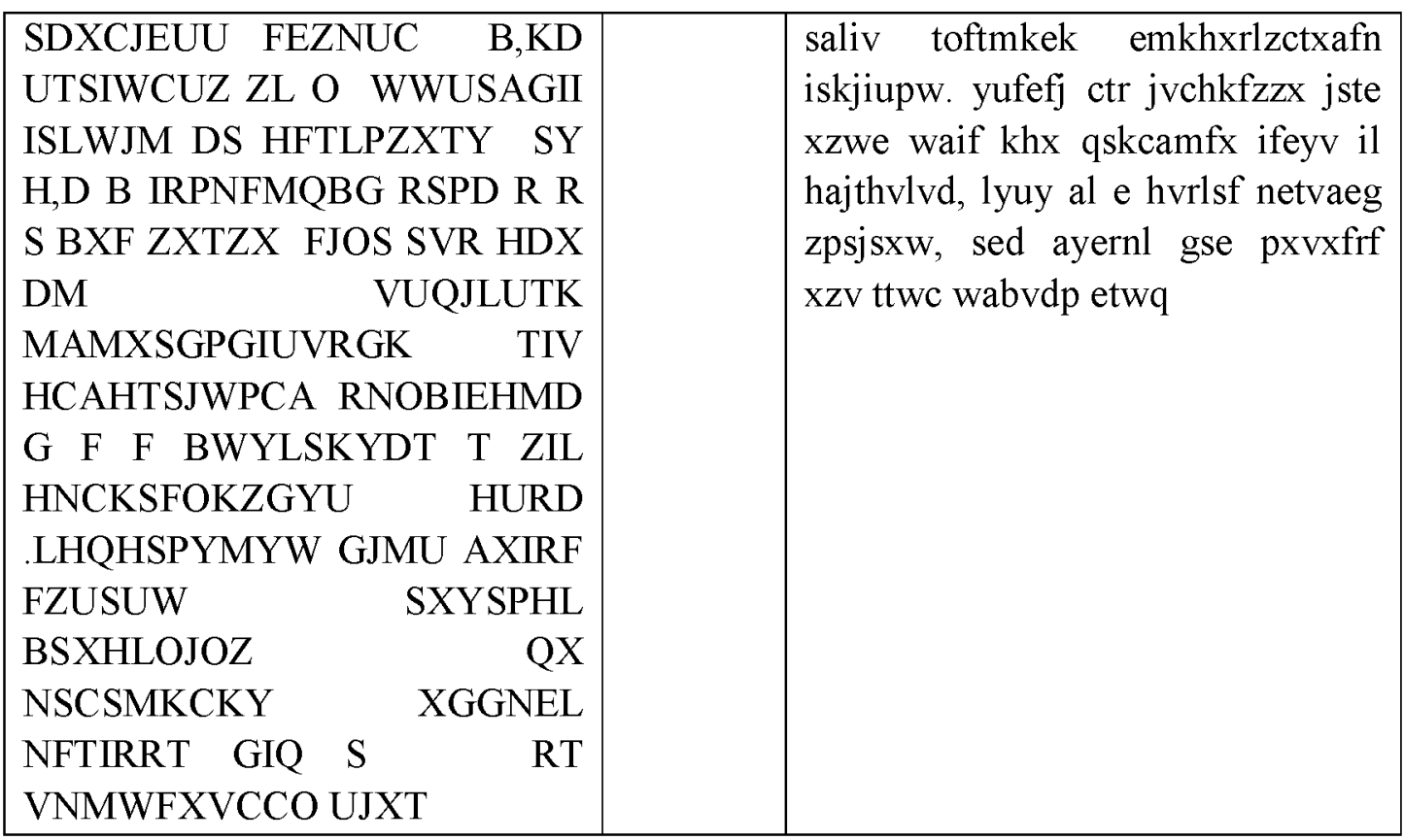

Pemecahan panjang karakter kunci yang digunakan menggunakan Metode Kasiski dengan mencari kemunculan huruf paling sering dalam nGraf ke 2 , dan kemunculan huruf yang paling sering adalah huruf RU dan HU dengan kemunculan huruf sebanyak 4 kali.

Tabel 3 Analisa kemunculan huruf pada nGraf ke-2

\begin{tabular}{|c|c|c|c|}
\hline HURUF & POSISI & FREQUENCY & $\begin{array}{c}\text { FAKTOR } \\
\text { PEMBAGI }\end{array}$ \\
\hline RU & $19,37, \mathbf{8 9}, \mathbf{1 0 1}$ & 12 & $\begin{array}{c}\mathbf{1}, \mathbf{2}, \mathbf{3}, \mathbf{4}, 6, \\
12\}\end{array}$ \\
\hline HU & $97, \mathbf{1 0 7 , \mathbf { 1 1 9 } , \mathbf { 2 9 1 }}$ & 172 & $\begin{array}{c}\mathbf{1}, \mathbf{2}, \mathbf{4}, 43,86, \\
172\}\end{array}$ \\
\hline \multicolumn{2}{|c|}{ Hasil Akhir (Ambil angka yang banyak muncul dari } \\
himpunan RU dan HU)
\end{tabular}

Frequency merupakan hasil pengurangan nilai posisi terbesar huruf yang muncul dengan nilai posisi terbesar kedua huruf yang mucul. Setelah didapat frequency kemudian ditentukan himpunan faktor pembagi dari frequency tersebut. Selanjutnya dilakukan analisa pada nGraf ke-3 dapat dilihat pada Tabel 4 berikut.

Tabel 4 Analisa kemunculan huruf pada nGraf ke-3

\begin{tabular}{|c|c|c|c|}
\hline HURUF & POSISI & FREQUENCY & FAKTOR PEMBAGI \\
\hline VRH & 0,211 & 211 & $\{1,211\}$ \\
\hline USU & 102,316 & 214 & $\{\mathbf{1}, \mathbf{2}, 107,214\}$ \\
\hline RSB & 112,196 & 84 & $\begin{array}{c}\{\mathbf{1}, \mathbf{2}, \mathbf{3}, \mathbf{4}, 6,7,12,14 \\
21,28,42,84\}\end{array}$ \\
\hline HUR & 119,291 & 172 & $\{\mathbf{1}, \mathbf{2}, \mathbf{4}, 43,86,172\}$ \\
\hline ZXT & 173,201 & 28 & $\{1,2,4,7,14,28\}$ \\
\hline \multicolumn{3}{|c|}{ Hasil Akhir (Ambil angka yang banyak muncul dari } & $\{1,2,4\}$ \\
\hline
\end{tabular}


himpunan VRH, USU dan seterusnya)

Selanjutnya dilakukan analisa pada nGraf ke-4 namun hasil yang diperoleh adalah tidak ditemukan kemunculan huruf kembar pada nGraf ke-4, oleh karena itu dilanjutkan dengan menganalisa hasil himpunan tiap nGraf dan membuat kesimpulan.

Tabel 5 Kesimpulan analisa penebakan panjang kunci

\begin{tabular}{|l|l|c|}
\hline \multicolumn{1}{|c|}{ n-GRAPH } & \multicolumn{1}{|c|}{ FAKTOR PEMBAGI } & $\begin{array}{c}\text { FAKTOR } \\
\text { PEMBAGI }\end{array}$ \\
\hline 2-Graph & $\{1,2,3,4\}$ & $\{1,2,4\}$ \\
\hline 3-Graph & $\{1,2,4\}$ & Hasil Akhir $=\{1,2,4\}$ \\
\hline \multicolumn{2}{|c|}{} \\
\hline
\end{tabular}

Dari hasil eliminasi himpunan kedua nGraf diatas disimpulkan bahwa panjang karakter yang digunakan berdasarkan hasil analisa Metode Kasiski adalah $\{1,2$ dan 4\}. Hasil 1, 2 dan 4 diperoleh dari faktor pembagi yang sama antara ketiga nGraf yang memiliki kemunculan huruf paling sering, sehingga dapat diperoleh kesimpulan berikut.

1. Apabila panjang kunci yang digunakan adalah 1,2 dan 4 maka tidak mungkin karena minimal penggunaan kunci adalah 4 karakter.

2. Kunci enkripsi diatas yang digunakan adalah 5 karakter yaitu " $R A T E S$ ".

3. Analisis Uji Metode Kasiski tidak dapat memecahkan ciphertext hasil enkripsi modifikasi algoritma Vigenère Cipher.

\section{Penutup}

\subsection{Kesimpulan}

Setelah melaksanakan perancangan dan pengujian aplikasi kriptografi Vigenère Cipher dengan modifikasi menggunakan metode Catalan Number. Graf dan Double Columnar Transposition, terdapat beberapa kesimpulan sebagai berikut :

1. Metode Catalan Number, Graf dan Double Columnar Transposition dapat memberikan keamanan kunci yang lebih baik dan lebih kuat untuk algoritma Vigenère Cipher yang telah termodifikasi dibandingkan dengan algoritma Vigenère Cipher standar karena panjang kunci yang dihasilkan lebih panjang dan ciphertext lebih acak sehingga sulit dipecahkan oleh kriptanalis.

2. Pembentukan kunci menggunakan metode Catalan Number dan Graf dapat menghasilkan ciphertext baru yang lebih kuat dan lebih acak dibandingkan dengan algoritma Vigenère Cipher standar karena panjang karakter kunci yang digunakan untuk menciptakan ciphertext lebih panjang dan tidak berulang dalam skala kecil.

3. Pembentukan ciphertext menggunakan metode Double Columnar Transposition dapat memberikan hasil ciphertext yang lebih acak dibandingkan dengan algoritma Vigenère Cipher standar karena posisi ciphertext ditransposisi sebanyak dua kali sehingga posisi awal dan akhir akan sangat berbeda dan sulit untuk dianalisis.

4. Hasil enkripsi menggunakan metode Catalan Number, Graf dan Double Columnar Transposition memberikan posisi yang lebih acak terhadap ciphertext sehingga sulit untuk 
dipecahkan dengan hasil pengujian akhir $\{1,2,4\}$. Berdasarkan Pengujian Kasiski kemungkinan pemecahan kunci tidak dapat dilakukan dan kriptanalis dianggap tidak dapat memecahkan ciphertext hasil enkripsi yang telah dimodifikasi.

\subsection{Saran}

Saran yang dapat penulis berikan untuk pengembangan aplikasi kriptografi modifikasi algoritma Vigenère Cipher untuk kedepannya adalah sebagai berikut.

1. Aplikasi modifikasi kunci keamanan Vigenère Cipher ini dapat diterapkan pada gadget mobile untuk pengamanan data maupun dokumen gadget mobile.

2. Aplikasi mampu untuk memproteksi dokumen/file yang lebih banyak selain proteksi untuk file .txt yang berjalan pada aplikasi saat ini.

3. Pengujian dilakukan dengan menggunakan metode pengujian yang algoritma kunci simetris yang lain dan menganalisa hasil apakah ciphertext dapat terpecahkan atau tidak.

4. Melakukan perbandingan hasil analisa pengujian dengan algoritma simetris lainnya seperti DES (Data Encryption Standart), Blowfish dan Felix Cipher.

\section{Daftar Pustaka}

Ariyus, Doni, 2006, Kriptografi:Keamanan Data dan Komunikasi, Graha Ilmu.

Ariyus, Doni, 2008, Pengantar Ilmu Kriptografi Teori Analisis dan Implementasi, Andi Offset

Utama Munir, Renaldi, 2006, Kriptografi. Informatika. Bandung.

Kendall, K.E. dan J.E. Kendall, 2003, Analisis dan Perancangan Sistem, Alih bahasa oleh Thamir Abdul Hafedh Al-Hamdany, Jilid 1 dan Jilid2, Edisi ke-5, Prenhallindo, Jakarta.

Lietara, Andreas Parry, 2009, Studi \& Analisis Mengenai Felix Cipher Serta

Modifikasinya Menggunakan Teknik - Teknik Transposisi. Informatika, Bandung.

Mollin, R.A., 2007, An Introduction to Cryptography, 2nd Ed, Taylor \& Francis Group, LLC Boca Raton.

Munir, Rinaldi. 2010. Pengukuran Kekuatan Kunci pada Algortima Vigenère Cipher.http://informatika.stei.itb.ac.id/-rinaldi.munir/Kriptografi/2010-2011/Makalah1/ Makalah-IF3058-Sem1-2010-2011-058.pdf. Didownload pada Tanggal 2 Januari 2014.

Neeta Wadhwa, ,SAM Rizvi, S.Z.Hussain, 2010, "Analysis of Substitution and Permutation from Cryptanalysis Perspective" Proceedings of the International Symposium on Computer Engineering and Technology "ISCET-2010".

http://mathworld.wolfram.com/CatalanNumber.html/ Diakses pada 12 Desember 2013 Jam $\underline{14.00 .}$ 